\title{
Stabilize ve kurutulmuş evsel arıtma çamurundan humik asit eldesi ve çim (Lolium Perenne L.) yetiştiriciliğinde kullanımı
}

\author{
Obtaining humic acid from stabilized and dried domestic sewage sludge and its \\ utilization in grass (Lolium Perenne L.) growth
}

\author{
Şule ORMAN', Hüseyin OK(D, Moilim FAHAD \\ Akdeniz Üniversitesi, Ziraat Fakültesi, Toprak Bilimi ve Bitki Besleme Bölümü, 07070, Antalya \\ Sorumlu yazar (Corresponding author): Ş. Orman, e-posta (e-mail): suleorman@akdeniz.edu.tr \\ Yazar(lar) e-posta (Author e-mail): huseyinok@akdeniz.edu.tr, mwalimfahade@yahoo.fr, aylinozgur@akdeniz.edu.tr
}

\section{MAKALE BILGİSİ}

Alınış tarihi 17 Ağustos 2020

Düzeltilme tarihi 17 Ekim 2020

Kabul tarihi 19 Ekim 2020

\section{Anahtar Kelimeler:}

Organik katı atık yönetimi

Humik asit

Çim

Gübre

Çevre kirlenmesi

\begin{abstract}
ÖZ
Ülkemizde son yıllarda çevre politikalarındaki düzenlemelere bağlı olarak kanalizasyon altyapılarına belediyeler ciddi yatırımlar yapmakta ve atık su arıtma tesislerinin sayıları gün geçtikçe artmaktadır. Arıtılan atık sular neticesinde ortaya çıkan arıtma çamuru miktarları da artış göstermektedir. Türkiye'de günlük kuru madde olarak üretilen arıtma çamuru miktarı ortalama 1000 ton civarında olup bertarafinda sorunlar yaşanmaktadır. Arıtma çamurları önemli miktarlarda organik madde ve bitki beslenmesi için gerekli makro ve mikro elementler içerdiklerinden dolayı toprak sslah materyali veya organik gübre olarak değerlendirilebilecek potansiyele sahiptir. Arıtma çamurunun ekosisteme güvenli bir şekilde geri kazandırılabilmesi için olumlu yönlerini güçlendiren yenilikçi çözümlere ihtiyaç olduğu düşüncesinden yola çıkılarak bu çalıșma planlanmıștır. Araştırmanın temel amacı; arıtma çamurunu direkt toprağa uygulamak yerine arıtma çamurundan üretilen humik asidi uygulayarak kullanımını güvenli hale getirmeye çalışmaktır. Bu amaçla, stabilize edilmiş ve kurutulmuş evsel arıtma çamurundan alkali/asit ekstraksiyonu ile elde edilen humik asitin toprağa uygulanması ile çim yetiştirilerek saksı denemesi yürütülmüş̧ür. Humik asit uygulamaları 4 tekerrürlü olarak 0,50 . $100,150,200 \mathrm{~kg} \mathrm{da}^{-1}$ toprak düzeylerinde yapılmıștır. Cim bitkilerinin boy, yas ağırlık, kuru ağırlık, SPAD klorofil metre okumaları, toplam klorofil analiz değerleri kontrole göre artış göstermiş ancak sadece SPAD değerleri istatistiksel olarak önemli bulunmuştur.
\end{abstract}

\section{ARTICLE INFO}

Received 17 August 2020

Received in revised form 17 October 2020

Accepted 19 October 2020

\section{Keywords:}

Organic solid waste management

Humic acid

Grass

Fertilizer

Environment pollution

\begin{abstract}
The municipalities have been making serious investments in sewer system infrastructures based on regulations in environmental policies in our country in recent years and the number of wastewater treatment facilities is increasing day by day. The increase in the refined wastewater amount also brings an increase in the amount of sewage sludge generated. In Turkey, the average amount of sewage sludge produced daily as dry substance is around 1000 tons. However, there are some problems with its elimination. Since sewage sludge contains organic substances at high amounts and also macro and micro elements necessary for plant nutrition, it has a potential to be utilized as soil reclamation material or organic fertilizer. Therefore, this study was planned based on the idea that innovative solutions were needed to strengthen the positive sides of sewage sludge for its safe recycling in the ecosystem. The main purpose of the research is to make the material safer for utilization by producing humic acid from sewage sludge and applying it to soil instead of applying sewage sludge directly to the soil. For this purpose, humic acid was obtained from stabilized and dried domestic sewage sludge by alkali / acid extraction. Humic acid produced was applied to the soil and a pot experiment was carried out by growing grass plants. Humic acid applications were made with 4 replicates at $0,50,100,150,200 \mathrm{~kg} \mathrm{da}^{-1}$ soil levels. Grass plants height, fresh weight, dry weight, SPAD chlorophyll meter readings, total chlorophyll analysis values increased compared to the control, but only SPAD values were found to be statistically significant.
\end{abstract}




\section{Giriş}

Ülkemiz toprakları bulunduğu iklim kuşağı nedeniyle organik maddece fakirdir. Organik madde ilavesi ile toprakta bir miktar iyileşme sağlansa da parçalanmanın hızlı olmasından dolayı bu etki uzun süreli olmamaktadır. Ülkemizde yoğun şekilde tarımsal üretim yapılmaktadır. Verimli ve kaliteli tarımsal üretim için topraklara düzenli olarak organik madde ilavesi yapılması bir zorunluluktur. Bu sebeple organik madde değerli ve kıt bir tarımsal girdidir.

Organik maddenin ayrışma ürünlerinin kendi aralarında reaksiyona girerek humin maddelerini meydana getirmesi olayına huminleşme veya huminifikasyon denir. Diğer bir deyişle, topraklara karışan organik materyallerin fiziksel, kimyasal ve biyolojik olarak ayrışması sonucunda toprak ve üzerinde yetiştirilen bitkiler için çok pozitif etkilere sahip olan "humus" oluşmaktadır. Humus; humik asit ve fulvik asit içeriği açısından zengin humik maddeleri içermektedir. Humik maddeler şekilsiz, kısmen aromatik ve çok iyi bir şekilde tanımlanan organik bileşikler gibi kimyasal ve fiziksel özelliklere sahip olmayan maddelerdir ve humik asitler (HAs), fulvik asitler (FAs) ve huminler olmak üzere 3'e ayrılır (Akıncı 2011). Humik ve fulvik asitleri içeren humik maddeler, toprak organik maddesinin en önemli bileşenidir (Chen ve Aviad 1990). Ayrıca diğer kaynaklardan gelen organik maddeye göre toprakta çok daha uzun süre kalmaktadır.

Humik maddelerin en önemli kısımlarından biri humik asitlerdir. Humik asitler ve fulvik asitler alkali ortamda çözünebilen "humus yapılarını" temsil ederler (Akıncı 2011; Ay 2015) (Şekil 1).

Humik asitler renkleri sarıdan siyaha değişen, bozulmaya dayanıklı, yüksek moleküler ağırlığa sahip, heterojen doğal kaynaklar olarak tanımlanmaktadır. Hayvan gübreleri, torf, linyitler, leonardit ve arıtma çamuru gibi organik kaynaklarda bulunmaktadır (Jackson 1994) (Çizelge 1).

Humik asitler, organik toprak düzenleyicisi olarak katı ya da sıvı formda bitkisel üretimde etkin bir şekilde kullanılmaktadır. Toprak organik maddesinin ayrışması ile oluşan humusun en aktif maddesi humik asittir. Bileşimlerinde karbon (C), oksijen $(\mathrm{O})$, hidrojen $(\mathrm{H})$ ve azot $(\mathrm{N})$ dışında önemli oranda karboksilik asit grupları, fenolik ve alkolik hidroksil keton ve kinon gibi yapıları barındırırlar. Humik asitin uygun konsantrasyonlarda kullanılması neticesinde bitki büyüme ve gelişmeleri üzerine olumlu etkileri bulunmaktadır. Humik maddeler pestisitler ve herbisitlerle etkileşerek kararlı yapılar oluştururlar, böylece
Çizelge 1. Doğal kaynakların içerdikleri toplam humik ve fulvik asit oranları.

Table 1. Total humic and fulvic acid ratios contained in natural resources.

\begin{tabular}{cc}
\hline Doğal Kaynak & Humik ve Fulvik Asit Oranları(\%) \\
\hline Leonardit & $40-90$ \\
Torf & $10-30$ \\
Linyit & $10-30$ \\
Hayvan gübresi & $5-15$ \\
Kompost & $2-5$ \\
Toprak & $1-5$ \\
Arıtma Çamuru & $1-5$ \\
Taş Kömürü & $0-1$ \\
\hline
\end{tabular}

bitkiler ve yeraltı suları için zararsız hale getirebilme özelliğine de sahiptirler (Öz Arık ve ark. 2016).

Humik materyaller bitki gelişimine olan farklı katkıları nedeniyle, toprak kimyası, toprak verimliliği, bitki fizyolojisi ve çevre bilimi gibi çok çeşitli alanlarda kullanılmaktadır (Chen ve Aviad 1990). Humik maddeler, katyonlarla şelat oluşturabilmeleri nedeniyle birçok besin elementinin alınabilirliğini artırarak, bu elementlerin bitkiye yarayışlılığı üzerine olumlu etki göstermektedirler (Stevenson 1994). Humik maddeler, kök ve kök tüyü gelişimini ve dolayısıyla kökün yüzey alanını artırmakta ve böylelikle bitkilerin potasyum $(\mathrm{K})$, fosfor (P) ve demir (Fe) gibi besin elementlerini alabilme kapasitelerini yükseltmektedir. (Marschner ve ark. 1986; Pinton ve ark. 1998; Cesco ve ark. 2000). Ayrıca humik asitin susuzluk, tuzluluk ve ağır metal stresleri gibi bitki büyümesi ve gelişmesinde olumsuzluğa neden olacak stres faktörlerinin azaltılmasında önemli bir mücadele ve destekleme materyali olduğu bilinmektedir (Akıncı 2011). Jindo ve ark. (2012) arıtma çamuru (AÇ), kompostlanmış arıtma çamuru (KAÇ), belediye katı atıkları (BKA) ve kompostlanmış belediye katı atık (KBKA)'larından alkali/asit ekstraksiyonu ile edilen humik asitin mısır bitkisinin kök gelişimi üzerine etkilerini inceledikleri çalışmalarında kontrole göre; kök alanı KBKA $>$ KAÇ $>$ BKA $>$ AÇ, ana kök büyümesi KAÇ $>$ KBKA $>B K A>A C ̧$, yanal kök büyümesi ve kök kuru ağırlığ $\mathrm{KBKA}>\mathrm{KAÇ}>\mathrm{BKA}>\mathrm{AÇ}$ şeklinde artış göstermiş̧tir. Araştırmacılar, kompostlanmış belediye katı atıkları ve kompostlanmış arıtma çamurundan elde edilen humik asitin daha erken ve daha verimli köklenme ile kısa sürede ve bol hasat sağlayıp, bariz ekonomik faydaları göz önüne alındığında, tarımda faydalı olacağı sonucuna varmışlardır.

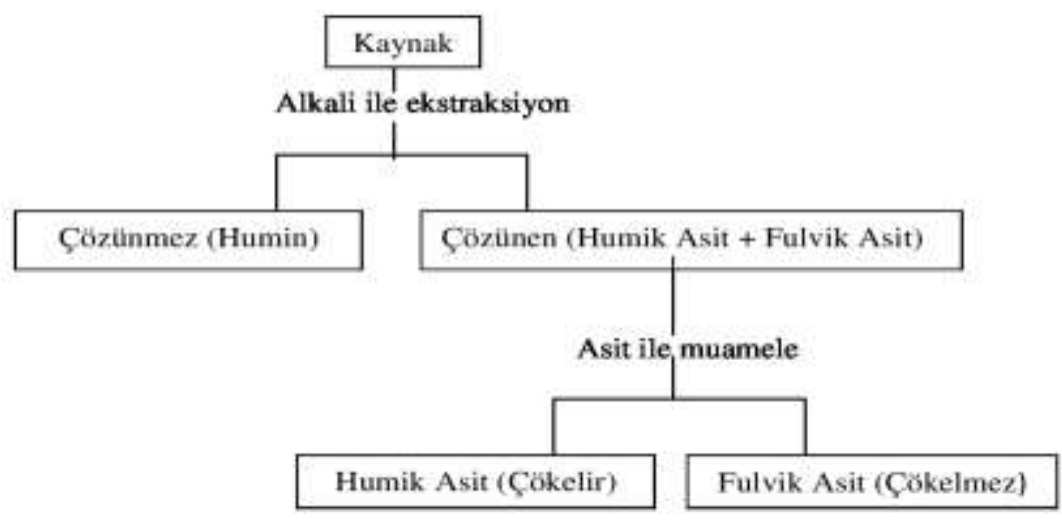

Şekil 1. Humik maddelerin kısımlarına ayrılması (Chen ve Avnimelech 1986).

Figure 1. Partitioning of humic substances (Chen ve Avnimelech 1986). 
Ülkemizde arıtma çamurunun toprakta kullanımına dair yönetmelikte; arıtma çamuruna, toprağa, bitkiye ve diğer çevresel faktörlere ait fiziksel, kimyasal ve biyolojik özellikler belirtilmiştir. Arıtma çamurunun ekosisteme güvenle geri kazandırılabilmesi için olumsuz özelliklerini iyileştirirken olumlu yönlerini güçlendiren yenilikçi çözümlere ihtiyaç duyulmakta olup $\% 70$ organik madde içeren arıtma çamurundan humik asit elde edilmesi ile ilgili çalışmaların önemli olduğu düşünülmektedir. $\mathrm{Bu}$ çalışmanın amacı stabilize edilmiş ve kurutulmuş arıtma çamurundan humik asit eldesi sağlamak ve çim bitkisi yetiştiriciliğindeki etkilerini ortaya koymaktır.

\section{Materyal ve Yöntem}

Çalışmada kullanılan humik asitin elde edildiği stabilize edilmiş ve kurutulmuş arıtma çamuru Antalya ilinin batı bölgesinin atık sularının arıtıldığı Antalya/Hurma İleri Atıksu Arıtma Tesisinden temin edilmiştir. Tesise günlük $160{\text { bin } \mathrm{m}^{3}}^{3}$ atık su gelmekte; yine günlük 150 ton arıtma çamuru ortaya çıkmakta ve stabilize edilmektedir. Oluşan çamurun 75 tonu tesiste kurutulmakta, peletlenmekte ve Konya Çimento'ya yakacak olarak kullanılmak üzere gönderilmektedir. Geriye kalan 75 tonu ise stabilize edilmiş ancak kurutulmamış çamur halinde bir özel sektör firmasına ton başına ücret ödenerek bertaraf edilmek üzere verilmektedir.

Arıtma çamurundan humik asit, Valdrighi ve ark. (1996)'na göre; aşağıdaki alkali/asit ekstraksiyonuna uygun olarak elde edilmiştir. Analiz için 100 gr stabilize edilip kurutulmuş arıtma çamuru tartılmış ve 1 litre $0.1 \mathrm{~N} \mathrm{KOH}$ çözeltisi ile 24 saat boyunca $180 \mathrm{dev} \mathrm{dk}^{-1}$ da çalkalanmıştır. Daha sonra elde edilen süspansiyon çözelti $5000 \mathrm{rpm}$ 'de $30 \mathrm{dk}$ boyunca santrifüj edilmiştir. Santrifüjden sonra filtre kağıdından vakum filtrasyona bağlanarak katı kısım ile sıvı kısım ayrılmıştır. Katı kısım atılmış ve elde edilen sıvının pH's1 $6 \quad \mathrm{~N} \quad \mathrm{H}_{2} \mathrm{SO}_{4}$ kullanılarak 2'ye ayarlanmıştır. pH'sı düşürülen çözelti $+4 \mathrm{C}^{0} \mathrm{de}$ karanlıkta 24 saat bekletilerek humik asitin floküle olması sağlanmıştır. Floküle olup şişenin dibine çöken humik asidi sıvı kısımdan tamamen ayırmak için 5000 rpm'de $30 \mathrm{dk}$ santrifüj edilmiştir. Elde edilen katı kısım humik asit ve sıvı kısım ise fulvik asittir. Humik asit saf su ile yıkanıp kurutulmuştur. Çalışmada toplam $600 \mathrm{~g}$ arıtma çamurundan $14 \mathrm{~g}$ humik asit elde edilmiştir. Arıtma çamurundan humik asit kazanımı aşağıda gösterildiği şekilde hesaplanmış ve $\% 2.3$ olarak belirlenmiştir.
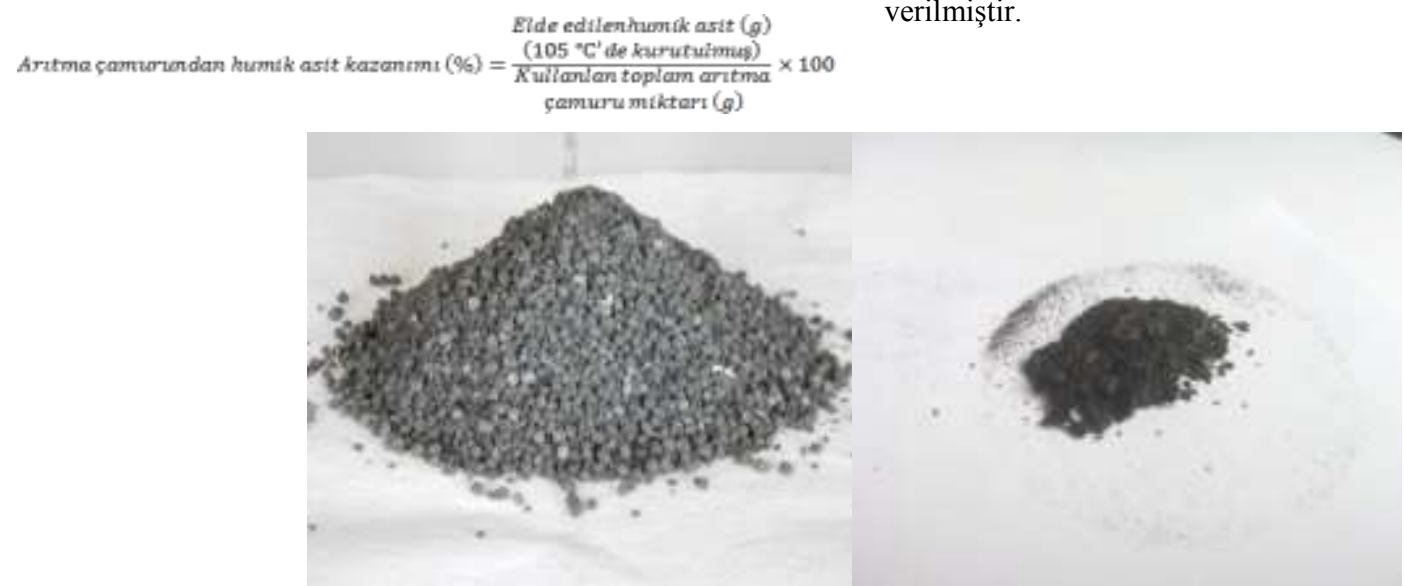

(a)

(b)
Denemede kullanılan toprağa ilişkin analiz sonuçları Çizelge 2'de verilmiştir.

Çalışma saksı denemesi olarak tesadüf parselleri deneme desenine göre 4 tekerrürlü olarak yürütülmüştür. Ağırlık ilkesine göre $500 \mathrm{~g}$ toprak içeren saksılara humik asit $0 \mathrm{~kg} \mathrm{da}^{-1}$, $50 \mathrm{~kg} \mathrm{da}^{-1}, 100 \mathrm{~kg} \mathrm{da}^{-1}, 150 \mathrm{~kg} \mathrm{da}^{-1}$ ve $200 \mathrm{~kg} \mathrm{da}^{-1}$ dozlarında karıştırılarak uygulanmıştır. Deneme bitkisi olarak İngiliz çimi (Lolium perenne L.) kullanılmıştır. Humik asit uygulamaları çim tohumlarının ekiminden 15 gün önce saksılardaki toprağa karıştırılmıştır. Saksılar 15 gün boyunca eşit bir şekilde sulanarak inkübasyona bırakılmıştır. Daha sonra $\mathrm{m}^{2}$ ye $80 \mathrm{~g}$ olacak şekilde çim tohumu ekimi yapılmıştır. Deneme 1 ay sürdürülmüş ve sonlandırılmadan önce bitkilerin boyları ölçülüp kaydedilmiştir. Ayrıca Minolta SPAD 502 Plus cihazı ile bitkilerin klorofil düzeyleri belirlenmiştir. Her saksıda bulunan çim bitkileri kök boğazlarından kesilerek yaş ağırlıkları tartılmıştır. Daha sonra kesilen bitkiler saf su ile yıkanmış bitki örnekleri $65^{\circ} \mathrm{C}$ de sabit ağırlığa gelinceye kadar kurutulmuş ve kuru ağırlıkları belirlenmiştir. Bitkiler kurutma dolabına bırakılmadan önce aynı gün alınan taze örnekte toplam klorofil analizi laboratuvar şartlarında gerçekleştirilmiştir (Williams 1984). Elde edilen veriler varyans analizine tabi tutulmuş ve ortalamalar arasındaki farklılık karşılaştırmaları Duncan testine göre belirlenmiştir.

Çizelge 2. Deneme toprağının bazı fiziksel ve kimyasal analiz sonuçları. Table 2. Results of analysis of experiment soil.

\begin{tabular}{lcl}
\hline Parametreler & Deneme Toprağı & \multicolumn{1}{c}{ Analiz Metotları } \\
\hline $\mathrm{pH}$ & 7.06 & Jackson 1967 \\
$\mathrm{EC}, \mathrm{dS} \mathrm{m}^{-1}$ & 0.80 & Soil Survey Staff 1951 \\
$\mathrm{CaCO}_{3} \%$ & 5.36 & Çağlar 1949 \\
Tekstür & Kum \% 78.16 & Bouyoucos 1955 \\
& Kil \% 9.28 (Kumlu Tın) & \\
Silt \% 12.56 & \\
Organik & 3.37 & Black 1965 \\
Madde, $\%$ & & \\
Organik & 1.96 & Tüzüner 1990 \\
Karbon, $\%$ & & Kacar 2009 \\
Toplam N, \% & 0.16 & \\
\hline
\end{tabular}

\section{Bulgular ve Tartışma}

Stabilize edilmiş ve kurutulmuş arıtma çamurunun ve elde edilen humik asitin (Şekil 2) bazı analiz sonuçları Çizelge 3'de verilmiştir.

Şekil 2. Stabilize ve kurutulmuş arıtma çamuru (a) ve elde edilen humik asit (b)

Figure 2. Stabilized and dried sewage sludge (a) and obtained humic acid (b). 
Çizelge 3'de görüldüğü üzere stabilize edilmiş ve kurutulmuş arıtma çamuru'nun pH'1 6.07 iken elde edilen humik asitin pH'1 2.31 olarak belirlenmiştir. Fernandez ve ark. (2009) tarafindan yapılan çalışmada kompostlanmış arıtma çamurundan elde edilen humik asitin pH'sının 3.94; 1 s1 kurutulmuş arıtma çamurundan elde edilmiş humik asitin pH'sının ise 3.05 olarak bulunmuş olup çalışmamız ile uyum göstermektedir. Elde ettiğimiz humik asitin organik madde düzeyi yüksek ve $\mathrm{C} / \mathrm{N}$ oranı'da Çizelge 4'de verilen değerlerle uyum göstermektedir. İncelenen parametreler değerlendirildiğine bitkisel üretim için toprağa uygulanabilecek olumlu özelliklere sahip olduğu düşünülmektedir. Arancon ve ark (2003) alkali/asit fraksiyonlama prosedürü kullanılarak sığır, gıda ve atık kağıt vermikompostlarından humik asitler ektrakte etmişler ve $400 \mathrm{~g}$ vermikomposttan $1 \mathrm{~g}$ kuru ağırlık humat elde ettiklerini bildirmişlerdir. Adani ve Tambone (2005) tarafından arıtma çamurlarının gübre görevi gördükleri için tarımda kullanılmakta olduğunun belirtildiği bir çalışmada; kontrol toprağına kıyasla, arıtma çamuru uygulanmış toprakta toplam organik C 'nun ve ilişkili humik fraksiyonların değişiklik göstermediğini; bununla birlikte, çamur uygulanmış toprağın humik asit (HA) bileşiminin, çamurun humik asit bileşimine yakın olarak tespit edildiğini bildirmişlerdir. Araştırmacılar, arıtma çamurunun toprak özellikleri üzerindeki etkisini, toprak organik maddesi özelinde değerlendirmek için uzun vadeli çalışmalara ihtiyaç olduğunu belirtmişlerdir.
Şekil 3'de görülen çim bitkilerinde 1 aylık yetiştirme periyodu sonunda Çizelge 5 'deki parametreler belirlenmiştir.

Bitkilerin SPAD cihazı ile klorofil ölçümünde toprağa arıtma çamurundan elde edilen humik asit uygulamalarının etkisi \%1 düzeyinde önemli bulunmuştur. Uygulama miktarları arttıkça ölçülen klorofil değeri artış göstermiştir. Laboratuvarda yapılan klorofil analizi neticesinde çim bitkisinin klorofil içeriği artış göstermiş, ancak istatistiksel olarak önemli bulunmamıştır. Aynı durum bitkilerin yaş ve kuru ağırlıkları ile boyları için de geçerli olmuş; toprağa humik asit uygulamaları ile bu değerler artış göstermesine rağmen istatistiksel olarak önemsiz bulunmuştur. Pilanalı ve Kaplan (2002) katı ve sıv1 formdaki humik asitlerin çilek meyve rengi üzerine önemli etkilerinin olmadığını belirtmişlerdir. Erdal ve ark. (2014) domates bitkisinin kuru ağırlığı üzerine humik madde uygulamalarının olumlu bir etkisinin olduğundan bahsetmenin mümkün olmadığını bildirmişlerdir. Arancon ve ark (2003) sığır, gıda ve atık kağıt vermikompostlarından elde ettikleri humik asitleri artan düzeylerde topraksız yetiştirme ortamı Metro-Mix (MM360)'e uygulayarak sera şartlarında kadife çiçeği, biber, çilek ve domates yetiştirmiş̧lerdir. Araştırmacılar bitkilerin yaprak alanları, bitki boyları ve üst aksamlarının kuru madde ağırlıklarının humik asit içeren saksılarda dikkate değer arttığını ancak bu artışların sadece MM360 (kontrol) içeren saksılarda yetiştirilen bitkilerden önemli düzeyde farklılık göstermediğini $(\mathrm{P} \leq 0.05)$ rapor etmişlerdir.

Çizelge 3. Arıtma çamurundan elde edilen humik asitin analiz sonuçları.

Table 3. Analysis results of humic acid obtained from sewage sludge.

\begin{tabular}{cccccc}
\hline Materyaller & $\mathbf{p H}_{\mathbf{H} 20}(\mathbf{1 : 1 0})$ & Organik Madde $\%$ & $\mathbf{C} \%$ & $\mathbf{N} \%$ & $\mathbf{C} / \mathbf{N}$ \\
\hline Arıtma Çamuru & 6.07 & 74 & 43.02 & 5.87 & 7.32 \\
Arıtma Çamurundan Elde Edilen Humik Asit & 2.31 & 98 & 56.97 & 6.06 & 9.40 \\
\hline
\end{tabular}

Çizelge 4. Arıtma çamuru ve leonarditten elde edilen humik asitin element içeriği.

Table 4. Element content of humic acid from sewage sludge and leonardite.

\begin{tabular}{|c|c|c|c|}
\hline \multirow{2}{*}{ Materyal } & \multicolumn{2}{|c|}{ Element İçeriği (\%) } & \multirow{2}{*}{$\begin{array}{c}\text { Atomik oran } \\
\mathrm{C} / \mathrm{N}\end{array}$} \\
\hline & $\mathbf{C}$ & $\mathbf{N}$ & \\
\hline Arıtma Çamurundan Humik Asit (L1 ve ark. 2013) & $57.22 \pm 0.26$ & $7.38 \pm 0.06$ & 9.0 \\
\hline Kompostlanmış Arıtma Çamurundan Humik Asit (Fernandez 2009) & $46 \pm 1$ & $8.5 \pm 0$ & 6.3 \\
\hline Isıl Kurutulmuş Arıtma Çamurundan Humik Asit (Fernandez 2009) & $50.3 \pm 3$ & $8.3 \pm 0$ & 7.1 \\
\hline Leonarditten Humik Asit (Ayuso ve ark. 1997) & 60.93 & 0.94 & 75.6 \\
\hline
\end{tabular}

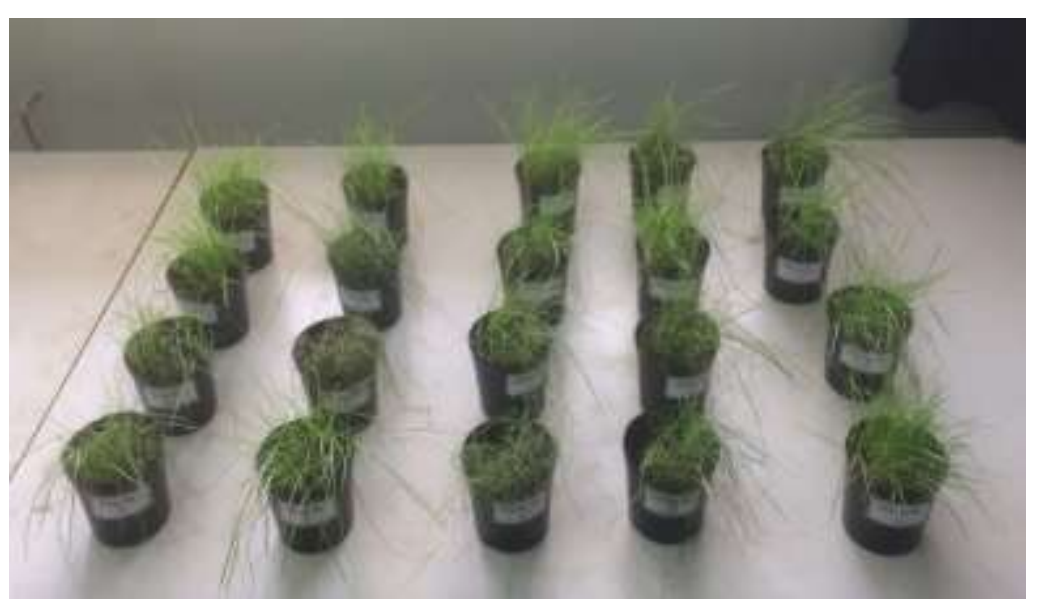

Şekil 3. Çim bitkilerinin kesilmeden önce genel görünümü. (Saksılar soldan sağa doğru: $0 \mathrm{~kg} \mathrm{da}^{-1}, 50 \mathrm{~kg} \mathrm{da}^{-1}, 100 \mathrm{~kg} \mathrm{da}^{-1}, 150 \mathrm{~kg} \mathrm{da}^{-1} \mathrm{ve}^{2} 200 \mathrm{~kg} \mathrm{da}^{-1}$ toprağa humik asit uygulamaları).

Figure 3. General view of grass plants before cutting (Pots from left to right: $0 \mathrm{~kg} \mathrm{da}^{-1}, 50 \mathrm{~kg} \mathrm{da}^{-1}, 100 \mathrm{~kg} \mathrm{da}^{-1}, 150 \mathrm{~kg} \mathrm{da}^{-1}, 200 \mathrm{~kg} \mathrm{da}^{-1} \mathrm{humic}$ acid applications to soil). 
Çizelge 5. Toprağa humik asit uygulamalarının Lolium Perenne L. çimi üzerine etkileri ${ }^{1}$.

Table 5. Effects of humic acid applications to soil on Lolium Perenne L.grass ${ }^{1}$.

\begin{tabular}{|c|c|c|c|c|c|}
\hline Uygulamalar (kg HA da $\left.{ }^{-1}\right)$ & SPAD Değerleri & Toplam Klorofil (mg g $\left.\mathrm{g}^{-1}\right)$ & Yaş Ağırlık (mg) & Kuru Ağırlık (mg) & Boy $(\mathbf{c m})$ \\
\hline $\mathbf{0}$ & $30.58^{\mathrm{b}}$ & 16.61 & 727.5 & 143 & 13.9 \\
\hline 50 & $38.85^{\mathrm{b}}$ & 15.52 & 585.0 & 148 & 14.0 \\
\hline 100 & $64.60^{\mathrm{a}}$ & 19.72 & 622.5 & 153 & 14.6 \\
\hline 150 & $53.13^{\mathrm{ab}}$ & 18.09 & 807.5 & 195 & 14.0 \\
\hline 200 & $67.08^{\mathrm{a}}$ & 21.20 & 1202.5 & 210 & 14.1 \\
\hline Önemlilik Düzeyi & $* *$ & ÖD & ÖD & ÖD & ÖD \\
\hline
\end{tabular}

${ }^{1}$ Değerler 4 tekerrür ortalamasıdır. Aynı harfle gösterilmeyen değerler arasındaki farklar \% 5 düzeyinde önemlidir. **:\% 1 düzeyinde önemlidir (P<0.01). ÖD: İstatistiksel olarak önemli bulunmamıştır.

\section{Sonuç}

- Bu araştırmada; arıtma çamurunun yüksek organik madde içeriğinden kaynaklanan olumlu etkilerini güvenli ve kullanımına izin verilebilir hale getirerek humik asit materyaline dönüştürmek üzerinde çalışılmıştır. Gerçekleştirdiğimiz kaynak taramaları neticesinde ülkemizde bu amaçla ilgili herhangi bir çalışmaya rastlanmazken, dünyada en az 30 y1l öncesinden günümüze doğru gelen çalışmalar bulunmuştur (Hernandez ve ark. 1990; Garcia ve ark. 1991; Fernandez ve ark. 2009; Azcona ve ark. 2011; L1 ve ark. 2013).

- Önümüzdeki yıllarda artan nüfus artışı ve atık su arıtma tesislerinin yaygınlaşmasının arıtma çamurlarını her zamankinden daha büyük bir sorun haline getireceği açıktır. Bu çalışmayla bu atığın çevreci, ekonomik ve sürdürülebilir olarak değerlendirilmesi hedeflenmiştir. Ayrıca organik atıkların değerlendirilmesi için uygun yöntemlerin bulunmasına katkı sağlayarak bertarafında zorluk çekilen arıtma çamuru için atık su arıtma tesislerine ve belediyelere çözüm ortağı olmak, gübre ve bitkisel üretim sektörüne alternatif organik madde kaynağ sağlamak da diğer hedeflerimiz arasındadır.

- Çok yönlü irdelendiğinde arıtma çamurundan elde edilen humik asitin doğru miktarlarda ve zamanlarda çim alanlarda kullanımının hem kimyasal gübre girdi maliyetlerini düşürecek ekonomik bir çözüm, hem yoğun kimyasal gübre uygulamalarından kaynaklanan su ve toprak kirliliğinin önlenmesi ve hem de atıklarımıza güvenli bir geri dönüşüm sağlayacak çevreci bir yaklaşım olduğu göz önünde tutulmalıdır.

- Başlangıç niteliğinde olan bu araştırmamızın daha büyük ölçekli çalışmalara doğru ilerleyerek ve elde edilecek sonuçlara bağlı olarak atık su arıtma tesislerine humik asit üretim tesislerinin de ilave edilerek bu atığın çok değerli olan organik madde içeriğinden düzenli bir şekilde yararlanılması ile ekonomik bir değere dönüştürülmesi için çalışmaların sürdürülmesinin gerekli olduğu düşünülmektedir.

\section{Teşekkür}

$\mathrm{Bu}$ çalışma, Akdeniz Üniversitesi Bilimsel Araştırma Projeleri Koordinasyon Birimi tarafindan bilimsel toplant1 kat1lımı "FYL-2017-2688" proje numaras1 ile desteklenerek 912 Mayıs 2018 tarihinde Konya'da gerçekleştirilen 9. Ulusal Katı Atık Yönetimi Kongresi'nde sözlü olarak sunulmuş ve özet olarak basılmıştır.

\section{Kaynaklar}

Adani F, Tambone F (2005) Long-term effect of sewage sludge application on soil humic acids. Chemosphere 60: 1214-1221.
Akıncı Ş (2011) Humik asitler, bitki büyümesi ve besleyici alımı. Marmara Üniversitesi Fen Bilimleri Dergisi 23(1): 46-56.

Arancon NQ, Lee S, Edwards CA, Atiyeh R (2003) Effects of humic acids derived from cattle, food and paper-waste vermicomposts on growth of greenhouse plants. Pedobiologia 47: 741-744.

Ay F (2015) Humik asit ve humik asit kaynaklarının jeolojik ve ekonomik önemi. Cumhuriyet Üniversitesi Fen Fakültesi Fen Bilimleri Dergisi 36: 28-51.

Ayuso M, Moreno JL, Hernandez T, Garcia C (1997) Characteristics and evaluation of humic acids extracted from urban wastes as liquid fertilizer. Journal of the Science of Food and Agriculture 75: 481488.

Azcona I, Pascual I, Aguirreolea J, Fuentes M, García-Mina JM, Sánchez-Díaz M (2011) Growth and development of pepper are affected by humic substances derived from composted sludge. Journal of Plant Nutrition of Soil Science 174(6): 916-924.

Black CA (1965) Soil-Plant Relationships. John Wily and Sons Inc., New York.

Bouyoucos GJ (1955) A Recalibration of the Hydrometer Method for Making Mechanical Analysis of the Soils. Agronomy Journal 4(9):434.

Cesco S, Nikolic M, Römheld V, Varanini Z, Pinton R (2002) Uptake of ${ }^{59} \mathrm{Fe}$ from soluble ${ }^{59} \mathrm{Fe}$ - humate complexes by cucumber and barley plants. Plant and Soil 241: 121-128.

Chen Y, Avnimelech Y (1986) The role of organic matter in modern agriculture. Martinus Nijhoof Publishers, Dordrecht.

Chen Y, Aviad T (1990) Effect of humic substances on plant growth. In: Maccarthy, P., Ed., Humic substances in soil and crop sciences: selected readings. American Society of Agronomy and Soil Sciences, Madison, 161-186.

Çağlar KÖ (1949) Toprak Bilgisi. Ankara Üniversitesi Ziraat Fakültesi Yayınları, Yayın Sayısı: 10.

Erdal İ, Küçükyumuk Z, Taplamacıoğlu D, Toftar B (2014) Kireçli bir toprakta humik ve fulvik asit uygulamalarının domatesin gelişimi ve beslenmesine etkileri. Toprak Bilimi ve Bitki Besleme Dergisi 2 (2): 70-74.

Fernandez JM, Senesi N, Plaza C, Brunetti G, Polo A (2009) Effects of composted and thermally dried sewage sludges on soil and soil humic acid properties. Pedosphere 19(3): 281-291.

Garcia C, Hernandez T, Costa F, Polo A (1991) Humic substances in composted sewage sludge. Waste Management \& Research 9: 189194.

Hernandez MT, Moreno JI, Costa F, Gonzales-Vila FJ, Frund R (1990) Structural features of humic acid like substances from sewage sludge. Soil Science 149: 63-68.

Jackson ML (1967) Soil chemical analysis. Prentice Hall of India Private Limited, New Delhi.

Jackson RW (1994) Enviro consultant service of evergreen, humic, fulvic and microbial balance: Organic soil conditioning, national first place nonfiction award from writer's Digest Journal, Colorado. 
Jindo K, Martim SA, Navarro EC, Perez-Alfocea F, Hernandez T, Garcia C, Aguiar NO, Canellas LP (2012) Root growth promotion by humic acids from composted and non-composted urban organic wastes. Plant and Soil 353: 209-220.

Kacar B (2009) Toprak Analizleri. Nobel Yayın No: 1387, Fen Bilimleri:90, Nobel Bilim ve Araştırma Merkezi Yayın No: 44 ISBN 978-605-395-184-1.

L1 H, L1 Y, L1 C (2013) Characterization of humic acids and fulvic acids derived from sewage sludge. Asian Journal of Chemistry 25(18): 10087-10091.

Marschner H, Römheld V, Kissel M (1986) Different strategies in higher plants in mobilization and uptake of iron. Journal of Plant Nutrition 9: 695-713.

Öz Arık U, Metin H, Aydın Ș, Yeğenoğlu ED (2016) Organic agriculture in Manisa-Alaşehir province and importance of humic acid. Uluslararası Katılımlı 3. Ulusal Humik Madde Kongresi, Konya, s. 175-189.

Pilanalı N, Kaplan M (2002) Çileğin meyve rengi ile farklı formlarda uygulanan humik asit ve toprağın bazı bitki besin maddesi kapsamları arasındaki ilişkilerin belirlenmesi. Yüzüncü Y1l Üniversitesi, Ziraat Fakültesi, Tarım Bilimleri Dergisi 12(1): 1-5.
Pinton R, Cesco S, De Nobili M, Santi S, Varanini Z (1998) Water and pyrophosphate-extractable humic substances as a source of iron for Fe-deficient cucumber plants. Biology and Fertility of Soils 26: 2327.

Soil Survey Staff (1951) Soil Survey Manual. Agricultural Research Administration, United States Department. Agriculture, Handbook No: 18.

Stevenson FJ (1994) Humus Chemistry: Genesis, Composition, Reactions. Second Edition. ISBN 0-471-59474-1, John Wiley\&Sons, INC., New York.

Tüzüner A (1990) Toprak ve Su Analiz Laboratuvarları El Kitabı. T.C. Tarım Orman ve Köyişleri Bakanlığı Köy Hizmetleri Genel Müdürlüğü s: 21-27.

Valdrighi MM, Pera A, Agnolucci M, Frassinetti S, Lunardi D, Vallini G (1996) Effects of composts derived humic acids on vegetable biomass production soil system: A Comparative Study. Agriculture, Ecosystems and Environment 58: 133-144.

Williams S (1984) Official methods of analysis of the association of official analytical chemist. Published by the association of official analytical chemist. Inc. Wircinia, 22 209, USA, s: 59-60. 